\title{
The solubility of sodium and potassium fluorides in strontium fluoride
}

\author{
P.P. Fedorov ${ }^{1,3}$, M. N. Mayakova ${ }^{1}$, V. A. Maslov ${ }^{1}$, A. E. Baranchikov ${ }^{2}$, V. K. Ivanov ${ }^{2}$, \\ A. A. Pynenkov ${ }^{3}$, M. A. Uslamina ${ }^{3}$, K. N. Nishchev ${ }^{3}$ \\ ${ }^{1}$ Prokhorov General Physics Institute, Russian Academy of Sciences, Moscow, 119991, Russia \\ ${ }^{2}$ Kurnakov Institute of General and Inorganic Chemistry, Russian Academy of Sciences, Moscow, 119991, Russia \\ ${ }^{3}$ Ogarev Mordovia State University, Saransk, 430005, Russia \\ ppfedorov@yandex.ru
}

DOI 10.17586/2220-8054-2017-8-6-830-834

The phase diagram of the $\mathrm{NaF}-\mathrm{SrF}_{2}$ system was studied by thermal analysis and X-ray powder diffraction analysis with the determination of the chemical composition. The system was found to be of the eutectic type. The eutectic co-ordinates are $853{ }^{\circ} \mathrm{C}, 32 \mathrm{~mol} \% \mathrm{SrF} 2 . \mathrm{A}$ narrow range of the existence of solid solution $\mathrm{Sr}_{1-x} \mathrm{Na}_{x} \mathrm{~F}_{2-x}$ was established. The NaF solubility reaches a maximal value of $x=0.035$ at eutectic temperature. The solubility of $\mathrm{KF}$ in $\mathrm{SrF}_{2}$ is very low.

Keywords: strontium fluoride, sodium fluoride, potassium fluoride, nanofluorides, $\mathrm{NaF}-\mathrm{SrF}_{2}$ phase diagram, solid solution.

Received: 10 November 2017

Revised: 15 November 2017

\section{Introduction}

The phase diagram of the $\mathrm{NaF}-\mathrm{CaF}_{2}$ system was studied in [1] by thermal and $\mathrm{X}$-ray phase analysis with control of the chemical composition. A narrow region of existence of $\mathrm{Ca}_{1-x} \mathrm{Na}_{x} \mathrm{~F}_{2-x}$ solid solution was revealed. The temperature dependence of $\mathrm{NaF}$ solubility in the strontium fluoride has a quirky character: it reaches a maximum value $x=0.035$ at $1200 \pm 50{ }^{\circ} \mathrm{C}$ (the temperature that corresponds to the diffuse phase transition in fluorite); it reaches a local minimum $\left(<0.4 \mathrm{~mol} \%\right.$ ) at $920 \pm 25{ }^{\circ} \mathrm{C}$, and again increases up to $2.2 \pm 0.2 \mathrm{~mol} \%$ at the eutectic temperature $\left(818^{\circ} \mathrm{C}\right)$.

Investigating the solubilities of sodium and potassium fluorides in strontium fluoride is of interest. Strontium fluoride is an important matrix for solid-state photonics, it is used in the form of melt grown single crystals [2-5], optical ceramics [6,7], and in nanotechnology processes [6-15]. In many synthetic processes, the ions of sodium and/or potassium are in the protocols [16]. Multicomponent ionic melts, including fluorides of strontium and alkali metals, are promising for use in metallurgy and nuclear power engineering [17].

Bukhalova and Berezhnaya studied the low-temperature parts of phase diagrams of the $\mathrm{NaF}-\mathrm{SrF}_{2}$ [18] and $\mathrm{KF}-\mathrm{SrF}_{2}$ [19] systems by method of visual polythermal analysis under the air. Systems belong to the eutectic type, the coordinates of the eutectics are $33 \mathrm{~mol} \% \mathrm{SrF}_{2}, 856{ }^{\circ} \mathrm{C}$ for the $\mathrm{NaF}-\mathrm{SrF}_{2}$ system and $22 \mathrm{~mol}^{\%}$ of $\mathrm{SrF}_{2}$, $744{ }^{\circ} \mathrm{C}$ for the $\mathrm{KF}-\mathrm{SrF}_{2}$ system. Regions near that of strontium fluoride have not been investigated. Precision measurement of $\mathrm{NaF}$ liquidus temperatures in the $\mathrm{NaF}-\mathrm{SrF}_{2}$ system was performed by Cantor [20]. Cryoscopic data [21] give no clear evidence for the formation of solid solution of sodium fluoride in strontium fluoride (as opposed to, for example, systems $\mathrm{CaF}_{2}: \mathrm{Na}$ and $\mathrm{BaF}_{2}: \mathrm{K}$ ). According to Bollman et al. [22] single crystals of melt grown strontium fluoride can contain up to $1.8 \mathrm{~mol} \% \mathrm{NaF}$, which leads to a drastic increase of ionic conductivity.

The aim of this work was to study the solubility of sodium and potassium fluorides in strontium fluoride, as well as clarifying the phase diagram of the $\mathrm{NaF}-\mathrm{SrF}_{2}$ system. In order to identify the region of solid solutions based on $\mathrm{SrF}_{2}$, in addition to the classic techniques of research, we used the technique of nanotechnology: previous investigations have shown that under low temperature syntheses, as a rule, non-equilibrium phases of variable composition are formed, with the width of the homogeneity region of solid solutions based on components often correspond to the limiting width of the high-temperature solid solutions, or even exceed it $[1,6,10,23-25]$.

\section{Experimental}

Sodium fluoride $\mathrm{NaF}$ (OS. h. 9-3); potassium fluoride bihydrate $\mathrm{KF}_{2} \cdot 2 \mathrm{H}_{2} \mathrm{O}$ (analytical grade 9-3); strontium chloride $\mathrm{SrCl}_{2}$ (Alfa Aesar); strontium nitrate $\mathrm{Sr}\left(\mathrm{NO}_{3}\right)_{2}$ purity 99.99\% (LANHIT company) were used as initial reagents for the synthesis as well as double distilled water.

Synthesis of samples was performed by coprecipitation from aqueous solutions at room temperature on the installation of periodic action. The main units of the set up for the synthesis are: the polypropylene reactor with a magnetic stirrer, and chemical feeder. The solutions of strontium nitrate $(0.15 \mathrm{~mol} / \mathrm{l})$ and a fluorinating agent 
$(0.25 \mathrm{~mol} / \mathrm{l})$ in doubly distilled water was prepared initially. To obtain precipitate, the aqueous solution of strontium nitrate was added dropwise to a solution of a fluorinating agent ( $\mathrm{NaF}$ or $\mathrm{KF}$ ). The equation of synthesis reactions is the following:

$$
(1-x) \operatorname{Sr}\left(\mathrm{NO}_{3}\right)_{2}+(2-x) \mathrm{MF}=\mathrm{Sr}_{1-x} \mathrm{M}_{x} \mathrm{~F}_{2-x} \downarrow+(2-2 x) \mathrm{MNO}_{3} .
$$

Mixing of solutions was carried out under permanent stirring with a magnetic stirrer. A suspension formed as a result of chemical reactions in the mother solution. The resulting precipitate was defended, decanted, washed with doubly distilled water until negative reaction of diphenylamine on the nitrate ions and dried under air at a temperature of $40-50{ }^{\circ} \mathrm{C}$.

To determine the limit of solubility for sodium and potassium fluorides in the $\mathrm{SrF}_{2}$ at elevated temperatures, we used the synthesis from chloride flux by the reaction

$$
(1-x) \mathrm{SrCl}_{2}+(2-x) \mathrm{MF}=\mathrm{Sr}_{1-x} \mathrm{M}_{x} \mathrm{~F}_{2-x} \downarrow+(2-2 x) \mathrm{MCl}
$$

The reagents were pre-dried, thoroughly mixed in agate mortar. Samples weight was $5.3 \mathrm{~g}$. The mixture was loaded into platinum crucibles $\left(10-20 \mathrm{~cm}^{3}\right)$, and then were dipped in shaft furnace, heated to $900-1100{ }^{\circ} \mathrm{C}$, kept for 10 minutes. The reaction product was washed with distilled water.

The morphology of the powders, prepared in accordance with reaction (2), is shown on Fig. 1. Habitus of powder particles suggests that the formation of microcrystals occurs by a non-classical crystal growth mechanism by oriented attachment of nanoparticles [26].
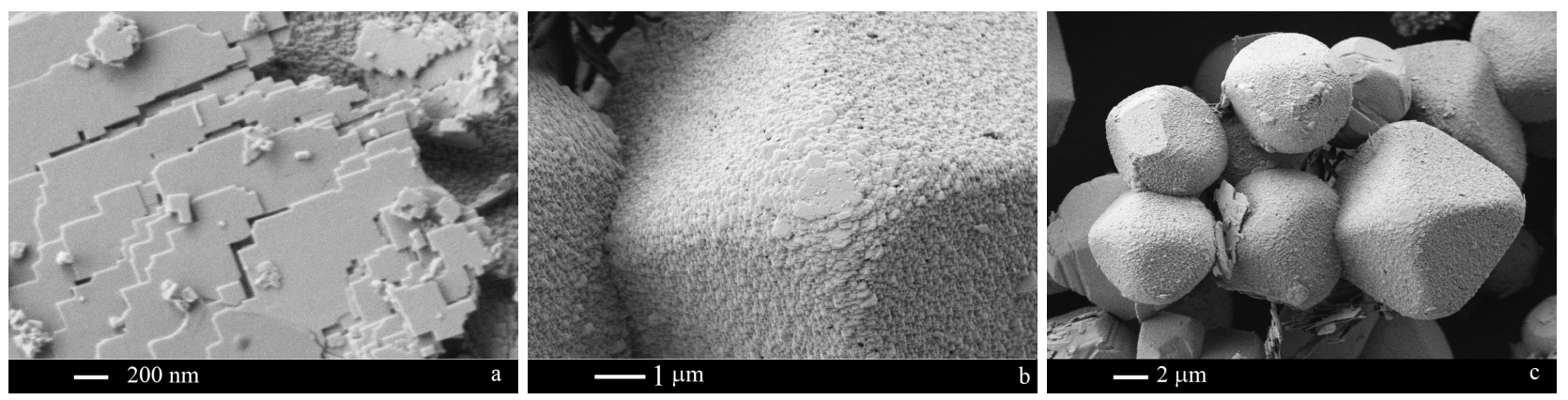

FIG. 1. Scanning electron microscopy image of a $\mathrm{SrF}_{2}$-based samples, obtained by chloride flux method: $\mathrm{a}-\mathrm{SrF}_{2}: \mathrm{Na}, 950{ }^{\circ} \mathrm{C} ; \mathrm{b}-\mathrm{SrF}_{2}: \mathrm{K}, 950{ }^{\circ} \mathrm{C} ; \mathrm{c}-\mathrm{SrF}_{2}: \mathrm{K}, 950{ }^{\circ} \mathrm{C}$

Differential scanning calorimetry (DSC) was performed on thermoanalyzer NETZSCH DSC 404 F1 Pegasus. The measurements were carried out in platinum crucibles under constant argon flow (20 $\mathrm{ml} / \mathrm{min})$; the heating rate was $10 \mathrm{~K} / \mathrm{min}$, and the cooling rate was $30 \mathrm{~K} / \mathrm{min}$. We analyzed carefully ground mixture of components, with weight of $\sim 30 \mathrm{mg}$. X-ray phase analysis was performed with the Bruker D8 Advanced diffractometer, CuK $\alpha$ radiation. Data processing was performed by software TOPAS. Electron microscope Carl Zeiss NVision 40 was used for carrying out scanning electron microscopy (SEM) and X-ray microanalysis (RSMA).

\section{Results and discussion}

Nanosized powders $\mathrm{Sr}_{1-x} \mathrm{Na}_{x} \mathrm{~F}_{2-x}$ and $\mathrm{Sr}_{1-x} \mathrm{~K}_{x} \mathrm{~F}_{2-x}$ were precipitated by the reactions (1). X-ray powder diffraction showed that the samples were single phase and had a cubic (fluorite-type) structure. The lattice parameters were slightly different from the lattice parameter of pure $\operatorname{SrF}_{2}$ (5.800 $\AA$, JCPDS card \# 06-0262). According to XRD, the size of coherent scattering regions $D=15 \pm 1 \mathrm{~nm}$ (see Table 1). RSMA showed the presence in the samples of $3.1 \mathrm{~mol} \% \mathrm{NaF}$ and $1.2 \mathrm{~mol} \% \mathrm{KF}$, respectively. Thus, wide areas of solid solutions on the basis of strontium fluoride in the systems $\mathrm{NaF}-\mathrm{SrF}_{2}$ and $\mathrm{KF}-\mathrm{SrF}_{2}$ are small.

After synthesis from a flux according to reaction (2), we obtained powders of fluorite structure with lattice parameters similar to those of $\mathrm{SrF}_{2}$ (Table 1). A small amount of sodium fluoride found only in the sample synthesized at $950{ }^{\circ} \mathrm{C}$. At $1000{ }^{\circ} \mathrm{C}$ sodium fluoride is not included in appreciable quantities in the lattice of $\mathrm{SrF}_{2}$. Admixture of potassium fluoride was not detected at all.

The constructed phase diagram of the $\mathrm{NaF}-\mathrm{SrF}_{2}$ system is shown in Fig. 2. Our data on this system matches well with previous studies of [18-20] in terms of the temperature of the eutectic equilibrium (our DSC measurements gave $853^{\circ} \mathrm{C}$ ), the curve of primary solidification (liqiudus) of the $\mathrm{NaF}$, and the composition of the eutectic 
TABLE 1. Characterization of the synthesized samples

\begin{tabular}{|c|c|c|c|c|}
\hline Composition & Preparation method & Lattice parameter, $\AA$ & MF content, mol \% & $D, \mathrm{~nm}$ \\
\hline \hline $\mathrm{SrF}_{2}: \mathrm{NaF}$ & Coprecipitation & $5.7991(3)$ & 3.1 & $15 \pm 1$ \\
\hline $\mathrm{SrF}_{2}: \mathrm{NaF}$ & Flux synthesis, $950{ }^{\circ} \mathrm{C}$ & $5.8001(5)$ & 1.4 & $>150$ \\
\hline $\mathrm{SrF}_{2}: \mathrm{NaF}$ & Flux synthesis, $1000{ }^{\circ} \mathrm{C}$ & $5.7995(9)$ & Not found & $>150$ \\
\hline $\mathrm{SrF}_{2}: \mathrm{NaF}$ & Flux synthesis, $1050{ }^{\circ} \mathrm{C}$ & $5.7988(4)$ & Not found & $>150$ \\
\hline $\mathrm{SrF}_{2}: \mathrm{KF}$ & Coprecipitation & $5.8031(2)$ & 1.2 & $15 \pm 1$ \\
\hline $\mathrm{SrF}_{2}: \mathrm{KF}$ & Flux synthesis, $950{ }^{\circ} \mathrm{C}$ & $5.8009(4)$ & Not found & $>150$ \\
\hline $\mathrm{SrF}_{2}: \mathrm{KF}$ & Flux synthesis, $1000{ }^{\circ} \mathrm{C}$ & $5.8001(5)$ & Not found & $>150$ \\
\hline $\mathrm{SrF}_{2}: \mathrm{KF}$ & Flux synthesis, $1050{ }^{\circ} \mathrm{C}$ & $5.8008(4)$ & Not found & $>150$ \\
\hline
\end{tabular}

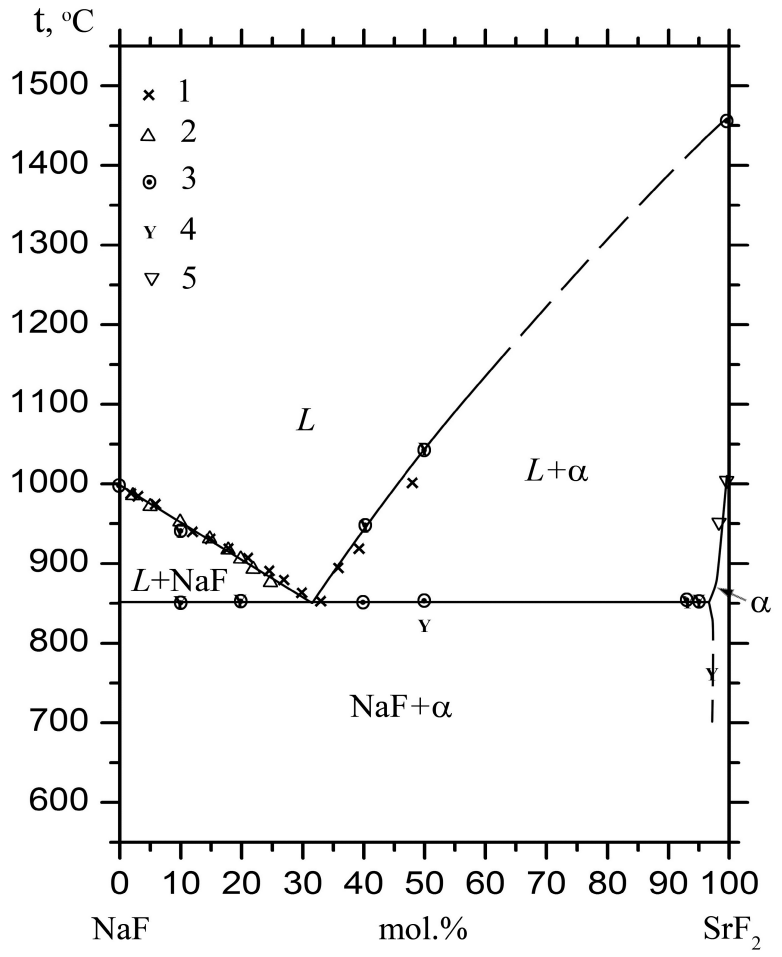

FIG. 2. Phase diagram of the $\mathrm{NaF}-\mathrm{SrF}_{2}$ system. 1 - data $[18,19] ; 2$ - data [20]; 3 - our data, DSC heating curves; 4 - our data, DSC cooling curves; 5 - our data, chemical analysis. $L$ melt, $\alpha$ - solid solution on the basis of $\mathrm{SrF}_{2}$

point $\left(32 \mathrm{~mol} \% \mathrm{SrF}_{2}\right)$. As for the $\mathrm{SrF}_{2}$ liquidus curve, there is a difference. This is due to the fact that the study of Bukhalova and Berezhnaya were carried out under air, and the process of partial pyrohydrolysis resulted in a lowering the apparent of $\mathrm{SrF}_{2}$ melting temperature.

The thermal effect of a eutectic is observed on the thermograms of samples containing 7 and $5 \mathrm{~mol} \mathrm{NaF}$, but it is not fixed for the composition with $3 \% \mathrm{NaF}$. For the last sample, the cooling curve after the second heating is fixed effect beginning with $760{ }^{\circ} \mathrm{C}$, which can be interpreted as the decomposition of the solid solution, see Fig. 2. Solid solution decomposition during cooling of the system is a consequence of the third law of thermodynamics [27].

Thus, we can conclude that the solubility limit of $\mathrm{NaF}_{\text {in }}$ the $\mathrm{SrF}_{2}$ is $3.5 \pm 0.5 \mathrm{~mol} \%$ at the eutectic temperature. The general formula of the solid solution can be written as $\operatorname{Sr}_{1-x} \mathrm{Na}_{x} \mathrm{~F}_{2-x}$ Then, the maximum solubility of sodium fluoride corresponds to $x=0.035$. 
In general, there was a negligible amount of sodium fluoride entry into the $\mathrm{SrF}_{2}$ lattice. The solid solution revealed was heterovalent, with a variable number of ions in the unit cell [28].

It is noteworthy that the chemical analysis showed the complete absence of KF in flux prepared samples of $\mathrm{SrF}_{2}$ phase (see Table 1).

The fluorite structure is loose; in it, cations occupy sites of an $f c c$ cubic close-packed lattice, anions are located at the centers of tetrahedral voids, and octahedral voids remain vacant. In all the known cases of isomorphism in the fluorite structure, the cation sublattice remains fully occupied. Substitution of a trivalent cation for a divalent cation by the reaction:

$$
\mathrm{M}^{2+} \longleftrightarrow \mathrm{R}^{3+}+\mathrm{F}^{-}
$$

is accompanied by the introduction of additional fluorine ions to the existing octahedral voids in the lattice, which leads to the formation of clusters of defects and to stabilization of the lattice. Conversely, the formation of anion vacancies during substitution of sodium for strontium by the reaction:

$$
\mathrm{Sr}^{2+}+\mathrm{F}^{-} \longleftrightarrow \mathrm{M}^{+}+\mathrm{V}_{F}
$$

causes loosening of the lattice and is undesirable from the crystal chemical standpoint. Note that simultaneous introduction of both trivalent and monovalent ions to the fluorite lattice by the reaction:

$$
2 \mathrm{Sr}^{2+} \longleftrightarrow \mathrm{R}^{3+}+\mathrm{M}^{+}
$$

which results in abrupt widening of the homogeneity ranges of fluorite solid solutions. This fact was revealed for the $\mathrm{NaF}-\mathrm{CaF}_{2}-\mathrm{RF}_{3}, \mathrm{NaF}-\mathrm{PbF}_{2}-\mathrm{BiF}_{3}, \mathrm{NaF}-\mathrm{BaF}_{2}-\mathrm{GdF}_{3}$ systems [1]. For strontium fluoride, there are only data for solid solutions of the type $\mathrm{NH}_{4} \mathrm{~F}-\mathrm{SrF}_{2}-\mathrm{RF}_{3}[11,29]$.

The formation of solid solution must be considered in thermodynamic modeling of phase equilibria in the system $\mathrm{NaF}-\mathrm{SrF}_{2}$ [17].

\section{Acknowledgements}

The authors express their appreciation V. V. Voronov for his kind assistance in the X-ray diffraction experiments. The authors also wish to thank E. V. Chernova for her help in the preparation of the present manuscript.

This work was partially supported by RFBR 15-08-02481-a grant.

\section{References}

[1] Fedorov P.P., Maykova M.N., et al. Phase diagram of the $\mathrm{NaF}_{-\mathrm{CaF}_{2}}$ system and the electrical conductivity of a CaF 2 -based solid solution. Russian J. Inorg. Chem., 2016, 61 (11), P. 1472-1478.

[2] Sobolev B.P. The Rare Earth Trifluorides. P.1. The High-Temperature Chemistry of the Rare Earth Trifluorides. Barcelona 2000, 520 pp.

[3] Fedorov P.P., Osiko V.V. Crystal Growth of Fluorides. In Bulk Crystal Growth of Electronic, Optical and Optoelectronic Materials. John Wiley \& Son, Ltd. 2005, P. 339-356.

[4] Basiev T.T., Orlovskii Yu.V., et al. Continuous tunable cw lasing near $2.75 \mathrm{~m}$ in diode-pumped $\mathrm{Er}^{3+}: \mathrm{SrF}_{2}$ and $\mathrm{Er}^{3+}: \mathrm{CaF}_{2} \mathrm{crystals}$ Quantum Electronics, 2006, 36 (7), P. 591-594.

[5] Alimov O.K., Basiev T.T., et al. Investigation of $\mathrm{Nd}^{3+}$ ions spectroscopic and laser properties in SrF 2 fluoride single crystal. Optical Materials, 2012, 34 (5), P. 799-802.

[6] Doroshenko M.E., Demidenko A.A., et al. Progress in fluoride laser ceramics. Phys. Stat. Solidi C, 2013,10 (6), P. $952-957$.

[7] Rozhnova Yu.A., Luginina A.A., et al. White light luminophores based on $\mathrm{Yb}^{3+} / \mathrm{Er}^{3+} / \mathrm{Tm}^{3+}-$ coactivated strontium fluoride powders. Mat. Chem. Phys., 2014, 148, P. 201-207.

[8] Fedorov .P., Luginina A.A., Kuznetsov S.V., Osiko V.V. Nanofluorides. J. Fluorine Chem., 2011, 132 (12), P. $1012-1039$.

[9] Luginina A.A., Fedorov P.P., et al. Synthesis of ultrafine fluorite $\mathrm{Sr}_{1-x} \mathrm{Nd}_{x} \mathrm{~F}_{2+x}$ powders. Inorg. Mater., 2012 , 48 (5), P. $531-538$.

[10] Mayakova M.N., Luginina A.A., et al. Synthesis of $\mathrm{SrF}_{2}-\mathrm{YF}_{3}$ nanopowders by co-precipitation from aqueos solutions. Mendeleev Communications, 2014, 24 (6), P. 360-362.

[11] Rozhnova Yu.A., Kuznetsov S.V., et al. New $\mathrm{Sr}_{1-x-y} \mathrm{R}_{x}\left(\mathrm{NH}_{4}\right)_{y} \mathrm{~F}_{2+x-y}(\mathrm{R}=\mathrm{Yb}$, Er) solid solution as precursor for high efficiency up-conversion luminophor and optical ceramics on the base of strontium fluoride. Math. Chem. Phys., 2016, 172 , P. 150-157.

[12] Yagoub M.Y.A., Swart H.C., et al. Surface characterization and photoluminescence properties of Ce ${ }^{3+}$, Eu Co-doped SrF 2 nanophosphor. Materials, 2015, 8, P. 2361-2375.

[13] Sun J., Xian J., Zhang X., Du H. Hydrothermal synthesis of $\mathrm{SrF}_{2}: \mathrm{Yb}^{3+} / \mathrm{Er}^{3+}$ micro-/nanocrystals with multiform morphologies and upconversion properties. J. Rare Earth, 2011, 29, P. 32-38.

[14] Sun J., Xian J., Du H. Facile synthesis of well-dispersed $\mathrm{SrF}_{2}: \mathrm{Yb}^{3+} / \mathrm{Er}^{3+}$ upconversion nanocrystals in oleate complex systems. Appl. Surf. Sci., 2011, 257, P. 3592-3595.

[15] Ritter B., Krahl T., Scholz G., Kemnitz E. Local structures of solid solutions $\operatorname{Sr}_{1 x} \mathrm{Y}_{x} \mathrm{~F}_{2+x}(x=0 \ldots 0.5)$ with fluorite structure prepared by SolGel and mechanochemical syntheses. J. Phys. Chem. C, 2016, 120, P. 8992-8999.

[16] Fedorov P.P., Luginina A.A., Popov A.I. Transparent oxyfluoride glass ceramics. J. Fluorine Chem., 2015, 172, P. 22-50.

[17] Renaud E., Robelin Ch., Gheribi A.E., Chartrand P. Thermodynamic evaluation and optimization of the $\left(\mathrm{LiF}+\mathrm{NaF}+\mathrm{KF}^{2} \mathrm{MgF} 2+\mathrm{CaF} 2\right.$ $+\mathrm{SrF}_{2}$ ) system. J. Chem. Thermodynamics, 2011, 43, P. 1286-1298. 
[18] Bukhalova G.A. The system Na, Sr, F, Cl. Izv. AN SSSR, Sektor fiz.-khim. analiza, 1955, 26, P. $138-146$ (in Russian).

[19] Berezhnaya V.T., Bukhalova G.A. Ternary systems of strontium fluoride with fluorides of alkaline metals. Zh. Neorg. Khimii, 1960, 5 (4), P. 925-929 (in Russian).

[20] Cantor S. Freezing point depressions in sodium fluoride. Effect of alkaline earth fluorides. J. Phys. Chem., 1961, 65, P. $2208-2210$.

[21] Delbove F. Application de la method cryometrique a haute temperature a letude de la formation de solutions solides dans les fluorures alcalino-terreux, a la limite de dilution infinite. Silicates Industriels, 1967, 32, P. 2659-2667.

[22] Bollmann W., Görlich P., Hauk W., Mothes H. Ionic conduction of pure and doped $\mathrm{CaF}_{2}$ and SrF 2 crystals. Phys. stat. sol. (a), 1970, 2, P. $157-170$.

[23] Fedorov P.P., Kuznetsov S.V., et al. Coprecipitation from aqueous solutions to prepare binary fluorides. Russian J. Inorg. Chem., 2011, 56 (10), P. 1525-1531.

[24] Fedorov .P., Mayakova M.N., et al. Co-precipitation of yttrium and barium fluorides from aqueous solutions. Mater. Res. Bull., 2012, 47, P. 1794-1799.

[25] Fedorov P.P., Mayakova M.N., et al. Synthesis of $\mathrm{CaF}_{2}-\mathrm{YF}_{3}$ nanopowders by co-precipitation from aqueos solutions. Nanosystems: Physics, Chemistry, Mathematics, 2017, 8 (4), P. 462-470.

[26] Ivanov V.K., Fedorov P.P., Baranchikov A.Y., Osiko V.V. Oriented aggregation of particles: 100 years of investigations of non-classical crystal growth. Russ. Chem. Rev., 2014, 83 (12), P. 1204-1222.

[27] Fedorov P.P. Third law of thermodynamics as applied to phase diagrams. Russ. J. Inorg. Chem., 2010,55 (11), P. 1722-1739.

[28] Fedorov P.P. Heterovalent isomorphism and solid solutions with a variable number of ions in the unit cell. Russ. J. Inorg. Chem., 2000, 45 (3), P. 268-291.

[29] Fedorov P.P., Kuznetsov S.V., Osiko V.V. Elaboration of nanofluorides and ceramics for optical and laser applications. In Photonic \& Electronic Properties of Fluoride Materials, Elsevier, 2016, P. 7-31. 